\title{
A utilização do vídeo como dispositivo metodológico na clínica da atividade docente
}

\section{The use of videotaping as a methodology device in the clinic of teaching activity}

\begin{abstract}
Resumo:
Este artigo narra uma experiência vivenciada em uma escola da Rede Pública de Ensino Escolar do município da Serra (Espírito Santo - Brasil). Na perspectiva da Clínica da Atividade, utilizou-se como abordagem metodológica a experimentação em autoconfrontação cruzada e filmagem das situações do trabalho docente como seu dispositivo. Foram filmadas situações de trabalho de duas professoras do ensino fundamental, elegendo-se a atividade de ensinar em sala de aula. O objetivo foi colocar em análise o trabalho docente e provocar um movimento de análise e coanálise do trabalho na escola. Apresenta as ações integradas que antecederam a filmagem bem como os diálogos produzidos a partir do processo de autoconfrontação cruzada disparados no e pelo coletivo constituído por pesquisadores, trabalhadores e gestores da educação no município da Serra. Destaca a relevância do dispositivo metodológico utilizado que coloca em questão os modos de trabalhar, perspectivando sua transformação sempre que se fizer necessário. Palavras-chave: Clínica da atividade docente. Trabalho docente - Autoconfrontação cruzada. Vídeo - Dispositivo metodológico.
\end{abstract}

Abstract:

This article narrates an experience in a Public School of Serra (Espírito Santo - Brazil). Based in a perspective of the Clinic of Activity, it was used as methodology a cruised auto confrontation experience and as device the videotaping of situations of teaching work. We observed work situations of two elementary school teachers focusing the activity of teaching in the classroom. The goal was to analyze teacher's work and instigate a movement of analysis and co-analysis of work in school. This text presents the integrated actions that preceded the videotaping and the dialogues produced by the process of cruised self-confrontation by the group consisting of researchers, workers and managers of education in the Public School System of Serra. Then, It's noteworthy the relevance of the methodological device used, which instigates analyses about the ways of working, looking ahead to its transformation whenever it's needed. Keywords: Clinic of teaching activity. Teaching work Cruised self-confrontation. Videotaping - Methodological device.

ROSEMBERG, Dulcinea Sarmento; BARROS, Maria Elizabeth Barros de; PETINELLI-SOUZA, Susane. A utilização do vídeo como dispositivo metodológico na clínica da atividade docente. Informática na Educação: teoria \& prática, Porto Alegre, v. 13, n. 1, p. 31-40, jan./jun. 2010.

\author{
Dulcinea Sarmento Rosemberg \\ Maria Elizabeth Barros de Barros \\ Susane Petinelli-Souza \\ Universidade Federal do Espírito Santo
}

\section{Iniciando conversas sobre o uso do vídeo como dispositivo metodológico...}

A s tecnologias de comunicação no contemporâneo têm colaborado para o aumento e circulação de um grande volume de informações. Ao mesmo tempo, algumas dessas tecnologias têm auxiliado o próprio processo de produção de dados em pesquisas científicas nas mais variadas áreas do conhecimento.

Ao resenhar o livro Desafios da Imagem, Mello (1999) informa que os anos 1980 são considerados como um marco para as ciências humanas e sociais, haja vista que se iniciou um processo de redimensionamento dos modos predominantes de produção de pesquisas. Isso fez com que os cientistas sociais percebessem os limites do alcance interpretativo dos modelos dominantes e buscassem outros regimes de produção de saberes. As ciências sociais e humanas passaram a incorporar especialmente os avanços dos novos suportes imagéticos. A autora referenciada diz que esse movimento das ciências promoveu o desenvolvimento da discussão em torno das novas bases teóricas e epistemológicas das 
ciências sociais a partir da incorporação de novos temas, objetos e estratégias ao campo de conhecimento dos cientistas sociais. Para Mello (1999), como decorrência, verificou-se um crescimento significativo de pesquisas que se vinculam à utilização de imagens, pela iconografia, fotografia, cinema ou vídeo.

Neste texto, buscamos narrar ${ }^{1}$ o processo que envolveu o uso do dispositivo de filmagem da atividade de ensino em uma pesquisa vivenciada em escola pública do município da Serra (Espírito Santo - Brasil), cujos vídeos oriundos do processo de filmagem contribuíram para a análise do trabalho docente no ensino fundamental dessa cidade.

Algumas experiências nesse campo começaram ainda nos anos 1950. Conforme relato de Cunha, Mata e Correia (2006), na obra Analyse du travail, de Ombredane e Faverge (1955), o uso do recurso de gravação de imagens e som na análise da atividade de trabaIho deu-se a partir de um pedido a esses autores que viram no filme uma possibilidade de difundir melhor as pesquisas desenvolvidas. No entanto, o referido filme não teve tanto impacto como a obra escrita, pois apenas recentemente foi redescoberto e analisado. Ainda assim, foi nessa ocasião que pela primeira vez, esse procedimento foi usado para buscar aproximações com o que se passava em contexto real de trabalho.

Os recursos imagéticos para pesquisas implicadas com uma abordagem compreensiva da atividade de trabalho, seja por meio da gravação de imagem e som em tempo real, seja pela manipulação (edição) do material gerado, podem redundar em filmes, documentários, vídeos, etc.

No entanto, as potencialidades de tais recursos como dispositivos metodológicos disparam algumas questões quanto ao seu uso: usar para quê? Como usar? Quando usar? Como evitar que os recursos imagéticos se transformem em estratégias de representação de uma realidade supostamente já dada? Ao realizar-se uma pesquisa utilizando como dispositivo a filmagem (imagem e som) das situações de trabalho, espera-se disparar diá-

1 Utilizamos aqui a expressão narrar e não relatar, uma vez que não temos a intenção de transmitir uma experiência pura em si como um relatório. Uma narrativa sempre se abre para a possibilidade de novos arranjos, permitindo criar outras histórias; narrar é criar, como nos indica Benjamin (1994). logos acerca dos modos de trabalhar nos ambientes laborais, de maneira a levar os trabalhadores a ampliar seu poder de agir para transformar o vivido em recurso de vivência de novas experiências (CLOT, 2006).

Reafirmamos, portanto, tomando-se as concepções de Clot (2000), Faïta (2005), Santorum (2006), Silva (2007), Amador (2009), Louzada (2009), entre outros autores, que os registros em vídeo auxiliam a condução do processo de análise e coanálise do trabalho. A partir deles podemos disparar um diálogo e construir discursos sobre o trabalho, dando visibilidade à atividade. $O$ vídeo assume, então, um papel determinante, porque viabiliza pensar sobre os elementos visíveis da atividade de trabalho, os quais podem servir para compreender outros elementos de que ela se reveste e que escapam à simples observação, por exemplo, o sentido das atividades impedidas ou contrariadas na vida dos trabalhadores (CLOT, 2006).

A imagem apenas permite, no entanto, ler uma das dimensões da actividade: à semeIhança de um iceberg (BARATTA, 1996), a filmagem apenas mostra a parte 'emersa', visível da actividade. Para [conhecer] os sentidos e significados das estratégias postas em prática, é preciso aceder aos trabalhadores, que nos explicitam os motivos e as opções que os guiam. De facto, uma das aplicações mais freqüentes da filmagem consiste na sua utilização para o desenvolvimento de entrevistas com os trabalhadores, favorecendo a recolha das suas apreciações e comentários emitidos face às estratégias que desenvolvem na actividade. As imagens contribuem para uma reflexão e um questionamento sobre os modos operatórios desenvolvidos em determinadas condições de trabalho, considerando que os saberes-fazeres dos trabalhadores nem sempre são conscientes, o que acaba por dificultar a sua verbalização através de um simples questionamento directo (BARATTA; BERTHET, 2000) (CUNHA; MATA; CORREIA, 2005, p. 25).

Para as autoras citadas, o confronto dos trabalhadores com as imagens do próprio exercício da atividade permite ainda desencadear o debate sobre os acontecimentos ou sequências que consideram mais significativas e contribui para atribuir um outro valor à palavra. Ao falar sobre a atividade de trabalho, podese levar à compreensão das potencialidades e das possibilidades de transformação das si- 
tuações de trabalho, uma vez que a filmagem faculta evidenciar elementos concretos, tangíveis, demonstrativos da atividade. Reiterase, portanto, que esses elementos tenderão a funcionar como argumentos úteis para os investigadores e trabalhadores-protagonistas que visem à transformação do meio de trabaIho. Como diz Clot (2000), a filmagem ainda é capaz de sedimentar os traços das mesmas atividades, a fim de que os trabalhadores-protagonistas das filmagens, cujas atividades estejam em análise, possam passar do estatuto de observados ao de observadores, coatores e também coautores na produção dos dados sobre o seu trabalho.

Nessa perspectiva, o vídeo em abordagens metodológicas, como a autoconfrontação cruzada, na medida em que pode ser tomado como instrumento de comunicação, revelase em um recurso importante no processo de formação profissional orientado para a transformação dos modos de trabalhar.

Apesar da justificativa da escolha do vídeo como dispositivo de produção de dados, é preciso, além de pontuar suas vantagens, ressaltar que tal dispositivo exige certos cuidados. Uma câmara sempre impacta, é um elemento estranho que carrega em si um conjunto de simbolismos que devem ser desmistificados com relação ao uso de filmagem em pesquisas científicas. Para isso, torna-se importante estabelecer uma negociação com os trabalhadores, partindo-se da premissa de que não é pretendido assumir o papel de controle do que eles fazem ou como fazem. Destaca-se ainda a relevância da colaboração e da adesão desses trabalhadores em pesquisas que convidam a usar a filmagem como dispositivo metodológico em análise do trabalho.

Os vínculos com aqueles que participarão da pesquisa e a construção de uma relação de confiança precisam ser artesanalmente tecidas desde o início do processo investigativo. A presença de câmeras, muitas vezes, tende a provocar uma sensação de desconfiança e desconforto na maioria dos indivíduos. Nesse instante, então, a clareza na definição dos objetivos da pesquisa poderá ajudar no processo de uso de filmadoras em ambientes de pesquisa. Ressaltamos, assim, que a participação ativa dos trabalhadores é um requisito essencial para o prosseguimento do trabalho de pesquisa, haja vista que o envolvimento deles no processo é vital para a passagem do estatuto de observados ao estatuto de observadores. E, também, para que, no momento de entrevista de autoconfrontação, o esclarecimento para o outro - neste caso, o investigador - seja facilitado (CLOT, 2000). A inclusão dos trabalhadores nesse processo de pesquisa sobre os ambientes laborais é o desafio das metodologias participativas, de forma que esse processo não seja apenas uma declaração de princípios.

É nessa fase que o diálogo entre investigadores e trabalhadores poderá levar à construção de uma concepção partilhada da situação de pesquisa. Mas o estabelecimento dessa relação participativa deve mobilizar não só os trabalhadores-protagonistas do vídeo, como também o próprio coletivo (grupo associado ou de referência). Esse último tem como função manter-se como interlocutor privilegiado e permanente da equipe de pesquisa. É no coletivo de trabalhadores que os encaminhamentos serão definidos a partir dos objetivos indicados no início da pesquisa, incluindo as discussões sobre os diferentes aspectos que envolvem a filmagem.

Esses argumentos têm instigado o uso do vídeo como dispositivo para colocar em discussão, em nosso caso, o trabalho e a saúde de docentes, acreditando na importância de construção de outros dispositivos metodológicos que deflagrem um regime de produção de saberes sobre o trabalho, que faça frente às novas configurações do capitalismo mundial.

\section{0 processo de filmagem das situações de trabalho docente}

O planejamento do processo de filmagem envolveu, como primeira ação do Grupo Associado, ${ }^{2}$ uma visita à escola escolhida, que foi feita pela equipe ${ }^{3}$ responsável por sua realização. Durante a ida à escola, buscou-se a familiarização com as crianças e professoras das turmas, e conhecer a local dos diferentes

\footnotetext{
2 Conforme Clot (2006), um grupo associado ou de referência tem como função manter-se como interlocutor privilegiado e permanente da equipe de pesquisa.

3 Composto por três pesquisadores do NEPESP-UFES e por dois especialistas, colaboradores nesta fase da pesquisa, sendo um radialista do Laboratório de Aprendizagem do Centro de Educação da UFES e um radialista da Rádio e Televisão Educativa do Espírito Santo.
} 
elementos, tais como: a posição das professoras e dos alunos na sala de aula; a área física e a localização de tomadas elétricas para estruturar a marcação do lugar para a fixação da câmera e dos respectivos ângulos de filmagem; o grau de iluminação e o nível de sonoridade ambiental, parâmetros julgados determinantes para a qualidade da filmagem. Nessa mesma perspectiva procuramos também assegurar as condições propícias à gravação dos diálogos entre professora e pesquisadores (autoconfrontação simples) e entre as duas professoras-protagonistas, diálogos esses mediados pelos pesquisadores (autoconfrontação cruzada). A disposição espacial ganha particular relevância nesses momentos de entrevista de autoconfrontação, já que vários elementos estarão presentes e a facilidade na visualização das imagens deve ser priorizada.

É certo que, com esses cuidados iniciais, não pretendemos - nem tínhamos como fazêlo, nem o desejamos - cercar todos os imprevistos ou sequer ambicionamos prever todas as potencialidades da pesquisa. Almejamos antes permitir aos investigadores orientar a sua atuação em função dos objetivos do estudo pela via da autoconfrontação cruzada. Objetivos orientados para a visualização e o acompanhamento do desenvolvimento das atividades que os professores realizam no dia a dia do seu trabalho. Na opinião de Clot (2006), mirando-se em um vídeo sobre o real da atividade, os trabalhadores passam a discutir sobre a atividade desenvolvida, vivenciando a oportunidade de repensar e transformar a própria atividade. Daí a aposta na tecnologia geradora de imagem e som (vídeo) como dispositivo metodológico, no caso, a filmagem da atividade docente.

As experiências vivenciadas pelos pesquisadores durante a filmagem revelaram que, de fato, elaborar um vídeo não é adaptar a realidade a ideias preconcebidas, mas, ao contrário, é estar aberto para lidar com os imprevistos e a variabilidade que a situação apresenta. Por exemplo, os ruídos que permanentemente chegam àquela sala de aula, provenientes de uma companhia de eletricidade, localizada próximo à escola, produziram nos pesquisadores e nos cinegrafistas, presentes na cena de filmagem, incertezas quanto à sua influência na qualidade do produto final. No entanto, no momento da edição do vídeo, por meio de medidas operacionais, esses ruídos foram minimizados, não ocasionando maiores transtornos à qualidade do áudio que, juntamente com as imagens filmadas, são fundamentais para garantir a análise e co-análise do trabalho.

Em seguida, promoveu-se o encontro dos docentes e pesquisadores com as situações de trabalho filmadas com o objetivo de selecionar as imagens que, posteriormente, resultariam na edição do vídeodispositivo responsável por disparar o processo de autoconfrontação simples entre a trabalhadora e os pesquisadores. Apesar de ter sido fértil em falas sobre as atividades filmadas, esse foi um momento perpassado por preocupações com a emissão de juízos de valor sobre o modo de atuação das duas professoras-protagonistas da atividade de ensinar. Esse fato induziu os pesquisadores a ressaltar que o foco da análise deveria estar voltado para a atividade de trabalho - ensinar - a ser desenvolvida em duas aulas para alunos de primeira e terceira séries do ensino fundamental.

\section{Narrando a experiência de autoconfrontação para a análise do trabalho docente...}

No estúdio de gravação encontram-se uma das professoras-protagonistas do vídeo que começa a ser exibido e um pesquisador, o mediador entre ela e as imagens do seu trabalho. No vídeo que está sendo exibido desenvolvese uma atividade de ensinar em que a professora e os alunos interagem o tempo todo: a professora fala e desloca-se entre as carteiras desarranjadas, os alunos movimentam-se sem parar. Num instante, a professora ensina utilizando o quadro de giz; em outro, dirige-se às carteiras, encurvando-se para corrigir as tarefas dos alunos. Entre uma correção e outra, pede silêncio, chama a atenção de alguns especificamente, convoca-os a sentarem-se, para logo em seguida, abrir um largo sorriso ao olhar o caderno de uma das alunas. $\mathrm{Na}$ sequência, mais uma vez, solicita silêncio, enquanto ajeita o uniforme de um, olha para outro e, delicadamente, pede que ele vista o casaco, ressaltando que está frio... Essas são cenas gravadas em uma manhã, numa sala de aula de primeira série do ensino fundamental que, dias depois, ao serem retomadas, revivi- 
das com o auxílio da tecnologia que as reproduzem, disparam o seguinte diálogo ${ }^{4}$ :

Pesquisador - Como é trabalhar (ensinar) tendo alguns alunos prestando atenção ao que você fala enquanto outros andam pela sala ou conversam com os colegas?

Professora - É um problema porque dificulta, atrapalha a aula. O tempo todo eu tenho que pedir para sentar... Olha! [diz a professora, reportando-se à cena que está sendo comentada]: Estão vendo? Já estou atendendo a três crianças e vem mais uma quarta me interrompendo.

Pesquisador - Você trabalha em pé desde a hora que aula começa até o final.

Professora - É um trabalho em que em nenhum momento eu sentei. É todo dia assim, de $7 \mathrm{~h}$ as 11h30min eu não sento... Aí, eu saio dali quebrada, cansada, muito cansada! Dá dor nas costas. Eu não sei, tenho vontade de pensar em outro [modo de trabalhar]. Como eu poderia atender aos alunos, por exemplo, sem precisar me encurvar assim... [Novamente ela aponta a imagem e verbaliza]: quer ver, gente, daqui a pouco estarei até com problema de coluna de tanto me curvar.

Pesquisador - Por que sente dor de cabeça, o que provoca essa dor?

Professora - Acho que é a tensão, né? Ansiedade de vê-los aprender, da vontade que sinto de ver os resultados do trabalho. Fico naquela ansiedade: dou atenção a um, dou atenção ao outro... Acho que é isso! Foi o que eu disse, a gente fica muito cansada, se estressa muito, tá entendendo?! Você vê que, em uma determinada hora, eu perdi a paciência com a menina... Isso acontece porque tem hora que você fica assim, sabe? Um chama, outro fala, outro levanta.

Pesquisador - Como é se confrontar com seu trabalho?

Professora - Eu vi que o meu trabalho está muito cansativo e que eu devo, a partir desse filme, procurar é um jeito de melhorar um pouco mais, melhorar pra mim e pra eles. Preciso buscar algo, não sei como, pensar em algo que possa fazer para melhorar, para não ficar tanto tempo en-

4 Os diálogos estão em itálico para diferenciar das citações. curvada, parando tanto para chamar a atenção deles. Acho que devo mudar minha postura um pouco, eu acho que tenho que sentar mais.

Dias depois, as mesmas cenas que provocaram os diálogos anteriormente enunciados, foram exibidas para a colega de trabalho par pertencente ao mesmo gênero profissional ${ }^{5}$ docente - com a presença da professoraprotagonista. Nessa etapa, denominada de autoconfrontação cruzada, diferentemente da autoconfrontação simples, os pesquisadores procuraram manter-se um pouco mais como observadores-expectadores dos diálogos entre as duas professoras. O vídeo começa a ser exibido, as professoras trocam olhares... Silêncio no estúdio, elas sabem que esse momento dialógico também está sendo filmado... Paira no ar certo constrangimento de ambas as partes. Aí os pesquisadores intervêm, ressaltam que o que está em análise é a atividade e não o desempenho pessoal. Aos poucos, entre sorrisos, uma delas inicia a conversa, dizendo: "Aquelas carteiras misturadas me incomodariam. Se fosse eu naquela sala, mudaria tudo, botava uma atrás da outra, certinho [referindo-se ao arranjo de carteiras enfileiradas], mas cada um tem jeito de trabalhar... eu não me vejo naquela sala de aula". Essa fala torna-se um tensor que provoca o diálogo entre as trabalhadoras:

Professora-protagonista - É a dinâmica dessa aula também, sabe? Eu prefiro os alunos [referendo-se aos alunos] mais juntinhos, pra um monitorar o outro, sabe? Para um ajudar, dar apoio mesmo ao colega.

Colega de trabalho - Não sei se isso é o tradicionalismo que está bem enraizado em mim, nesse sentido de comportamento: você tem que entrar num ambiente e tem que estar organizado. Daquela forma ali [apontando a imagem] você olha e, na verdade, não sabe qual aluno que está conversando, que está te incomodando e que pode estar atrapalhando, porque eles estão muito juntos, misturados. Então, quando é assim, como é que você vai controlar o aluno,

5 Gênero, a partir da formulação da Clínica da Atividade, é o arcabouço cultural de uma categoria profissional em cujo bojo seus representantes encontram experiências, regras e um saber que norteia o seu fazer. Esse gênero permite que os trabalhadores encontrem suporte para suas errâncias e experimentações (CLOT, 2007). Diríamos que é o que delimita e particulariza a experiência do labor. É condição de possibilidade de trabalho. 
né? Por que tem que ter o controle pra ele, tá! É preciso você saber que ele está aprendendo e você passando. Se você os deixa muito soltos, aí não vai ter noção daquele que conseguiu pegar, daquele que não alcançou, daquele em que você precisa chegar, entendeu? Eu achei assim, muito disperso.

Pesquisador - Que sentido faz para você essa forma de funcionar indicada pela colega [dirigindo-se à professora-protagonista]?

Professora-protagonista - Depois que eu vi o vídeo, mudei minha postura... Não mudei o meu jeito de trabalhar, meu jeito de trabalhar atendendo a todos. Mas, porém, pedindo para cada aluno aguardar a vez. Acho bom o modo de operação dela em sala de aula [referindo-se à fala do par especialista, no caso, da colega de trabalho]. Ela fala de organização da sala de aula, mas eu sou mais liberal no meu modo de trabalhar, é o meu jeito mesmo de trabalhar [enfatiza].

O dispositivo metodológico, qual seja, a filmagem das situações de trabalho, criou condições para que as professoras, ao verem-se em atividade laboral, pudessem estabelecer diálogos entre/com os outros (pesquisadores e colega de trabalho), mas também delas consigo mesmas. A exibição do vídeo contendo as situações de trabalho antes analisadas individualmente (autoconfrontação simples) e, depois, a sua retomada em autoconfrontação cruzada, leva as duas professoras a concordarem "[...] que o que está sendo vivido na atividade de trabalho vem produzindo adoecimento". Colocaram também em questão a disposição das cadeiras, a forma como a atividade pedagógica estava sendo conduzida: "A disposição da sala de aula faz a diferença na liberdade que a professora está tendo para andar entre os alunos", indicando que a organização do espaço físico também influencia os modos de trabalhar na escola, especialmente, em sala de aula.

Como diz Clot (2000, 2006), a autoconfrontação cruzada relança o discurso no coletivo de trabalho, tornando o trabalho um objeto do pensamento. Ao verem as imagens da sua atividade, as professoras colocam em análise os modos de trabalhar e os efeitos produzidos pelas estratégias criadas, exercitando o pensamento, indagando formas, muitas vezes, sacralizadas de agir e pensar. Nesse sentido, acreditamos que, ao verbalizarem sobre a atividade de trabalho, as professoras se deparam com a complexidade do que fazem, do que não fazem, mas também com aquilo que poderiam fazer e deixaram de fazer.

A pesquisa indica, ainda, que os alunos experimentam diferentes dinâmicas de aula e que os professores produzem diferentes modos operatórios, ao mesmo tempo em que escapam de algumas formas prescritas de funcionamento na escola. As prescrições são necessárias para o funcionamento das atividades, porém é impossível aos seres humanos sujeitarem-se totalmente a elas. Para a realização das atividades, é preciso espaço para a interpretação e invenção. É no entre o prescrito e o real que está a nascente da criação, da engenhosidade, da gestão do trabalho.

As professoras, que pertencem ao mesmo gênero profissional, lidam com situações de trabalho de modos específicos e, nessas situações, estabelecem certas relações. Programas e planos de ensino comporiam aquilo que é da ordem da tarefa, mas, também, para o que é da ordem da invenção em frente ao imprevisível e comporta o estilo que se torna, "[...] por sua vez a transformação dos gêneros, por um sujeito, em recursos para agir em suas atividades reais." (CLOT, 2006, p. 50)

Quando um trabalhador está em situação não prevista e é preciso inventar uma solução, essa invenção corresponde ao estilo. Contudo, essa invenção se produz na experiência concreta, ou seja, em situação de trabalho, ela se efetiva com base em um patrimônio, um gênero profissional.

Na pesquisa realizada o vídeo serviu como disparador da discussão sobre o trabalho docente e, consequentemente, sobre esse gênero profissional. As professoras puderam discutir com seus pares, em momentos posteriores, sobre o que gera sofrimento na atividade de trabalho e, sobretudo, sobre as ações que podem minimizar ou mesmo evitar o processo de adoecimento. As trabalhadoras perceberam a importância de momentos como esses, de pausas para pôr a atividade em análise, cuja produção de sentido induziu o interesse por encontros coletivos na escola, com periodicidade mensal, objetivando discutir o trabalho e trocar experiências.

A experiência com os docentes reafirma, assim, uma aposta metodológica que, a partir 
da Clínica da Atividade, contribui para pensar a atividade do sujeito como se dirigindo para a atividade dos outros e para suas outras atividades, isto é, reafirma que a atividade do sujeito não se volta unicamente para o objeto da tarefa. Clot (2006) nos diz que, quando uma atividade de trabalho é privada de um destinatário, ela perde o seu sentido, o que implica afirmar que o destinatário atribui sentido ao trabalho. Ainda fazendo uma outra inflexão, diríamos que as luzes precisam ser jogadas nas relações que se efetivam nos processos de trabalho. Consequentemente, afirmamos que os mundos do trabalho não podem ser estudados a partir de metodologias que privilegiam os princípios da representação de realidades tidas como dadas, uma vez que o cotidiano laboral apresenta-se como uma complexa rede que se tece no curso da atividade. Por conseguinte, vai à contramão de uma postura que assume que, na análise dos mundos do trabaIho, é possível saber, para prever a fim de agir, que se expressa no paradigma do conhecer para, então, transformar.

Logo, as metodologias de pesquisa pautadas na representação, usadas para investigar os mundos do trabalho, mostram-se ineficazes quando se busca dar visibilidade às estratégias que os docentes criam e inventam para dar conta de relações de trabalho mais potentes, e isso só se faz acompanhando o curso da atividade desenvolvida na situação de trabalho.

Por fim, nos estudos realizados por nós, na Rede Municipal de Ensino do município da Serra (ES), destacamos o esforço de retomada do problema da experiência definida como atividade. A Clínica da Atividade é uma aposta nesse sentido, o que pode ser verificado na montagem do projeto de Yves Clot com sua rede de interlocuções, quando se afirma que analisar o trabalho é mais do que avaliar a resposta dos trabalhadores às prescrições. Só é possível analisar o trabalho considerando o modo singular como o trabalhador atualiza a atividade em uma experiência. Tal ênfase na experiência singular da atividade do trabalho permite a inflexão proposta pelo autor para uma Clínica da Atividade. O trabalho se realiza como contínua aprendizagem que só se efetiva por meio da experiência. Mas que experiência é essa que podemos dizer singularizadora do trabalho: a experiência do labor?

Perguntar o que singulariza a experiência do labor é retomar a discussão com Yves Clot.
O conceito de gênero profissional indica um tipo particular da experiência, isto é, o gênero para Clot (2006) indica a singularidade da experiência do labor. Como a experiência pode se dar como um gênero? O que seria um gênero da experiência? O gênero poderia ser pensado, em uma primeira aproximação, como aquilo que delimita, já que particulariza a experiência. Tal delimitação tem uma versão prescritiva que Clot (2006) define como impessoal. No entanto, essa impessoalidade não pode ser considerada apenas em sua face normativa e estanque. A forma da atividade própria de um gênero não pode estar apartada dos outros planos. O gênero profissional deve ser pensado como graus de abertura tal como um diafragma que aumenta ou diminui a expressão dos planos pessoal, interpessoal e transpessoal. O gênero, portanto, nunca está dado, mas vai se construindo no processo de transversalização dos planos, sendo, a cada momento, uma diferença no modo de trabalhar geradora de diferenciações da atividade de labor - uma diferença diferenciante. O gênero é uma condição de possibilidade do trabalho e, nesse sentido, é prévio como uma prescrição. No entanto, essa condição prévia não pode ser considerada como definitiva, pois ela também vai se modificando no fluxo da experiência. Podemos, então, pensar o gênero como um a priori histórico na acepção que Foucault (1999, 2008) dá a esse conceito.

Por conseguinte, tomar o trabalho como atividade nos obriga a uma aposta metodológica em que a pesquisa e a intervenção não se separam. Essa aposta se expressa ao retomarse a máxima socioanalítica: não conhecer para transformar, mas transformar para conhecer, uma vez que os processos de construção de conhecimento e de transformação se dão juntos. O pesquisador, a investigação e o ambiente pesquisado se constituem num processo de coengendramento. O próprio Clot (2006) afirma que, quando observamos, deixamos traços no observado. Investigar a experiência em sua potência ontogenética (criação e modificação da realidade) desafia o pensamento a superar o modelo da representação, apostando no caráter enativo ${ }^{6}$ da cognição. Conhecer não é representar a realidade de dado objeto, mas

6 Enativo refere-se a uma cognição corporificada. Não é
cognição como processo mental, mas como resultante da cognição como processo mental, mas como resultante da
experiência que se inscreve no corpo. 
é lançar-se em uma experiência de criação de si e do mundo. Nessa perspectiva, conhecer a experiência do trabalho, realizar a clínica da atividade requer que façamos do trabalho de pesquisa uma escuta da experiência do trabaIho. Investigar a atividade de trabalho é buscar uma experiência oculta que o trabalhador detém malgrado ele mesmo? Há algo no trabalhador que precisa ser explicitado? Se assim supomos, a experiência do investigar não é ela mesma uma ação criadora da realidade, servindo apenas como mediação ou acesso à experiência a ser desvelada. Diferentemente, consideramos que a investigação como atividade é criação da atividade por ela estudada.

A pesquisa da atividade do trabalho é um acesso à experiência do labor na medida em que a investigação é ela mesma uma experiência que se distingue e não se separa daquela estudada. É tal plano que une as experiências daquele que investiga e daquele que é investigado que precisa ser considerado nas metodologias de investigação dos processos de trabalho. Falamos de um êthos, de uma postura do pesquisador. Como as tecnologias de imagem podem ajudar-nos nessa direção ético-política? Esse é um dos desafios que a utilização dos recursos imagéticos como dispositivos metodológicos nos colocam, ou seja, não tomar tais recursos como estratégias de representação da realidade, mas sim como dispositivos para investigar a experiência o que não se faz sem a inclusão daqueles com os quais pesquisamos no processo de investigação. Para Amador:

É num ir e vir, por entre obscurescências e iluminação, que as imagens se presentificam e se (re)presentificam num processo interminável e não cumulativo. É por digressão que se opera por desvio e por diminuição perceptiva que se processa a imagem; por um ir e vir numa zona de intervalo na qual a matéria se presentifica por um trabalho da percepção pura molecularizada, e se (re)presentifica, pela percepção consciente que temos dela por uma totalidade. Por esta razão, a presentificação imagética é uma espécie de implosão de sua consciência, de abertura de rasgos em sua superfície, uma vez que ela só é possível se, ao menos uma vez, a imagem tiver entrado na representação. Do mesmo modo, opera a afecção, já que essa apenas é disparada mediante um trabalho perceptivo. Ela é o que se mistura do nosso corpo à imagem dos corpos exteriores, sendo aquilo que - enquanto espécie de impureza - devemos extrair da percepção para reencontrar a pureza da imagem. Perfurar a espessura da imagem-percebida pela afecção, tendo a memória como travessia a qual, duran- do, faz sobreviver imagens passadas pela lembrança modificando o presente e fazendo persistir o trajeto, possibilitando, assim, a invenção do mundo. Numa quase simultaneidade com as afecções, a memória exerce, assim, uma função de acréscimo, oferecendo elementos ao traçado do próprio futuro, no sentido de dar corpo à atualização do virtual, figurando, portanto, como veículo de ação e não como substrato de um conhecimento. Trata-se de uma memória que recusando uma função puramente (re)depositária, tem a potencialidade de pôr mundos; de oferecer algo diferente pelo déjà vu, porém constituindo um jamais vu. (AMADOR, 2009, p. 60)

Assim, não se trata simplesmente de inverter a formulação representacional, o que é insuficiente para dar conta da questão metodológica envolvida na investigação da experiência do trabalho. A investigação do labor só inventa a atividade do labor na medida em que esta última aceita a participação da outra nessa invenção, ou seja, na medida em que elas entram em núpcias e se reinventam mútua e localmente, num devir a-paralelo. Como diria Deleuze $(1997,1998,2000)$ onde diferem sem se separar. Dito de outra forma: o protagonismo da investigação depende do protagonismo conjunto do objeto. Justamente, é em uma metodologia representacional que pode acontecer em parte uma sobrecodificação perigosa da atividade estudada, substituindo-Ihe o sentido imanente por um significado tirânico transcendente. Uma investigação na direção que indicamos deve dar primazia à expressão dos sentidos que a própria atividade cria e recria incessantemente, quando ela não se submete em demasia a um ponto de vista heterônomo. Consideramos que a investigação é tão inventada por seu objeto, quanto ela o inventa. Por isso essa direção metodológica contém o paradoxo capaz de nos tirar da alternativa estanque descobrir/inventar e nos colocar diante da invenção que nunca se faz sem núpcias e onde coemergem ou são coinventadas atividades de investigação e atividades estudadas.

Essas são questões da maior importância quando nos jogamos na construção de metodologias que se propõem a analisar o trabalho como atividade, como processo de criação de si e do mundo. Aqui, apenas anunciamos alguns aspectos que a pesquisa desenvolvida nos coloca, uma vez que pode levar a transformar o meio de trabalho, cuja transformação se enuncia nas narrativas de alguns professores presentes ao encontro, que visou a socializar 
o conhecimento produzido com eles:

[...] deu para perceber que somos donos da nossa própria história! Não me esqueço do depoimento da [cita o nome de uma das trabaIhadoras que teve sua atividade filmada] sobre as dores na coluna provocadas por ter que se encurvar em cada carteira para corrigir as tarefas dos alunos. Fez-me lembrar de uma dor no joelho que eu tinha durante a semana e que passava no final de semana. A dor era efeito de uma forma de fechar um armário existente na sala de aula [...]. Hoje estou feliz porque estou aqui falando sem microfone! Comecei a compartilhar o trabalho de ensinar com outro colega o que me levou a poupar a voz [aqui ela se refere ao fato de uma das professoras-protagonistas chamar a atenção dos alunos o tempo todo].
É importante o espaço coletivo não apenas para pensar a saúde do professor, mas também para contribuir com a escola em seus vários sentidos [...]. Nenhuma política, por melhor que seja ela, será eficiente sem um espaço coletivo de discussão. Outro trabalhador-professor-pesquisador também enfatiza que [...] o espaço coletivo não pode representar corporativismo, pelo contrário, deve contribuir para debater os projetos político-pedagógicos, mas também a organização do trabalho na escola.

Essa pesquisa me ajudou muito porque me fez ter coragem para discutir as questões dentro da escola no coletivo. Isso foi muito bom, pois o grupo consegue sugerir soluções para questões que nos afligem e, muitas vezes, nem sabemos que aflige o outro também.

\section{Referências}

AMADOR, F.S. Entre Prisões da Imagem, Imagens da Prisão um Dispositivo Tecno-poético Para uma Clínica do Trabalho. 2009. Tese (Doutorado em Informática na Educação) - Programa de Pós-Graduação em Informática na Educação da Universidade Federal do Rio Grande do Sul, 2009, Porto Alegre,BR-RS.

BENJAMIN, W. O Narrador. In: BENJAMIN, W. Magia e Técnica, Arte e Política: ensaios sobre literatura e história da cultura. Tradução de Sérgio Paulo Rouanet. 7. ed. São Paulo: Brasiliense, 1994. V. 1, p. $197-221$. (Obras escolhidas).

CLOT, Y. A Formação Pela Análise do Trabalho: por uma terceira via em maneiras de agir, maneiras de pensar em formação. Tradução de Claudia Osorio da Silva, Kátia Santorum e Suyanna Barker. Paris: CNAM, 2000.

CLOT, Y. A Função Psicológica do Trabalho. Petrópolis: Vozes, 2006.

CUNHA, L.; MOTA, R.G.; CORREIA, F. Luz, Câmara, Acção: orientações para a filmagem da actividade real de trabalho. Laboreal, Porto, v. 2, n. 11, p. 24-33, 2006. Disponível em: <http://laboreal.up.pt/revista/artigo> Acesso em: 18 dez. 2008.

DELEUZE, G. Diferença e Repetição. Lisboa: Relógio D'água, 2000.

DEleuZE, G. GUATTARI, F. Mil Platôs: capitalismo e esquizofrenia. São Paulo: Ed. 34, 1997. V. 4.

DELEUZE, G.; PARNET, C. Diálogos. São Paulo: Escuta, 1998.

FAÏTA, D. Análise Dialógica da Atividade Profissional. Rio de Janeiro: Ed. do Autor, 2005.

FOUCAULT, M. As Palavras e as Coisas: uma arqueologia das ciências humanas. 8. ed. São Paulo: Martins Fontes, 1999.

FOUCAULT, M. A Arqueologia do Saber. 7. ed. Rio de Janeiro: Forense Universitária, 2008.

LOUZADA, A.P. Um Trabalho Docente: a invenção como imanente à vida. 2009. Tese (Doutorado em Educação) - Programa de Pós-Graduação em Educação, Universidade Federal do Espírito Santo, 2009, Vitória, BR-ES. 
MELLO, M.T.V.B. Os Usos da Imagem nas Ciências Sociais. Revista de Estudos Históricos, Rio de Janeiro, v. 13, n. 23, p. 214-219, 1999. Resenha do livro "Desafios da Imagem" organizado por Bela Feldman-Bianco e Miriam L. Moreira Leite e publicado pela Papirus, São Paulo, 1998.

SANTORUM, K.M.T. Pelas Fendas do Trabalho Vivo: textos, contextos e ato na atividade de vigilância em saúde do trabalhador. 2006. Tese (Doutorado em Saúde Pública) - Centro de Estudos da Saúde do Trabalhador e Ecologia Humana, Escola Nacional de Saúde Pública Sérgio Arouca, Fiocruz, 2006, Rio de Janeiro, BR-RJ.

SILVA, C.O. da. Trabalho e Perspectivas Clínicas. [S.I.:s.n.], 2007. Trabalho apresentado no XI Colóquio Internacional de Psicossociologia e Sociologia Clínica, Belo Horizonte, 2007.

Recebido em maio de 2010.

Aprovado para publicação em junho de 2010

\section{Dulcinea Sarmento Rosemberg}

Doutoranda do Programa de Pós-Graduação em Educação da Universidade Federal do Espírito Santo (Ufes)/Vitória -ES/Brasil. Professora do Departamento de Ciências da Informação da Ufes e pesquisadora do Núcleo de Estudos e Pesquisa em Subjetividade e Política (Nepesp) da Ufes, Vitória - Espírito Santo - Brasil.

Email: dsrosemberg@globo.com.

\section{Maria Elizabeth Barros de Barros}

Pós-doutora em Saúde Pública (ENSP). Professora dos Programas de Pós-Graduação em Educação e em Psicologia Institucional da Universidade Federal do Espírito Santo (Ufes) e coordenadora do Nepesp-Ufes. Vitória - ES/Brasil.

Email: betebarros@uol.com.br

\section{Susane Petinelli-Souza}

Doutoranda do Programa de Pós-Graduação em Educação da Universidade Federal do Espírito Santo (Ufes). Professora do Departamento de Administração da Ufes, pesquisadora do Núcleo de Estudos de Tecnologias de Gestão e Subjetividades (Netes-Ufes) e do Nepesp-Ufes. Vitória - ES/Brasil.

Email: susipetinelli@gmail.com. 